\title{
Framework Conceitual para a Construção de Interfaces Persuasivas Educacionais
}

\author{
Raquel Machado Leite ${ }^{1}$, Regina Barwaldt ${ }^{1}$ \\ ${ }^{1}$ Centro de Ciências Computacionais - Universidade Federal do Rio Grande (FURG) \\ Caixa Postal 474 - 96.201-900 - Rio Grande - RS - Brazil \\ tpraquelegmail.com, reginabarwaldtefurg.br
}

\begin{abstract}
This work presents a conceptual framework as a strategy for the construction of persuasive educational interfaces, establishing connections between the areas of psychology and computation. It is based on exploratory and descriptive research. The interaction explored from the induction techniques, according to the needs, can transform the educational reality, making student life more attractive and applicable.
\end{abstract}

Resumo. Este trabalho apresenta um framework conceitual como estratégia para a construção de interfaces persuasivas educacionais, estabelecendo conexões entre as áreas da psicologia e da computação. Baseia-se na pesquisa exploratória e descritiva. A interação explorada a partir das técnicas de indução, de acordo com as necessidades, pode transformar a realidade educacional, tornando a vida estudantil mais atrativa e aplicável.

\section{Introdução}

Historicamente a educação é centrada em um processo no qual o professor é o detentor do conhecimento e o aluno segue a teoria para que a construção do saber tenha significado. Porém, nesse contexto, Penido (2016, p. 24), escreve que "o modelo de escola que conhecemos expirou. Deixou de fazer sentido para boa parte dos estudantes, estressa os professores, não gera os resultados esperados, nem consegue preparar as novas gerações para enfrentar os desafios da vida contemporânea". Na intenção de colaborar com a transformação da realidade educacional, demostrando alternativas que reduzam a distância entre prática em sala de aula e vida cotidiana, este trabalho concebe um framework conceitual para a construção de interfaces persuasivas educacionais como estratégia computacional para a personificação do ensino, baseando-se na investigação exploratória e descritiva.

\section{Métodos}

Parte do princípio da pesquisa exploratória e descritiva, segundo Gil (2008) e Kobashi e Santos (2006) visa dar maior conhecimento sobre o problema, detalhando e descrevendo suas peculiaridades. Foi realizada a revisão da literatura a partir dos repositórios digitais relacionados à área, baseado no que foi proposto por Kitchenham et. al. (2009) que menciona a Revisão Sistemática da Literatura como uma considerável investigação de um fenômeno relevante que produz resultados característicos por meio da interpretação de conteúdo e qualidade do material pesquisado. 
VI Congresso Brasileiro de Informática na Educação (CBIE 2017)

Anais dos Workshops do VI Congresso Brasileiro de Informática na Educação (WCBIE 2017)

\section{Resultados}

Segundo Araújo (2013, p.42) framework conceitual é um "conjunto de conceitos que se inter-relacionam, orientam uma investigação, determinando o escopo e a lógica do uso de certos conceitos para a solução de problemas". O Quadro 1 reproduz o framework conceitual para a construção de interfaces persuasivas, subdividindo-se em categorias com encadeamento de ideias centrado nas áreas da Psicologia e da Computação.

Quadro 1. Framework Conceitual Psicologia x Computação

\begin{tabular}{|c|c|c|c|}
\hline \multicolumn{2}{|r|}{ Psicologia } & \multicolumn{2}{|r|}{ Computação } \\
\hline Descrição & Processo de interação & Descrição & Processo de interação \\
\hline $\begin{array}{l}\text { Concepções da } \\
\text { Engenharia } \\
\text { Cognitiva }\end{array}$ & $\begin{array}{l}\text { Variáveis: psicológicas } \\
\text { (objetivos e intenções), físicas } \\
\text { (estado do sistema) e controles } \\
\text { físicos (mecanismos de } \\
\text { interação). } \\
\text { Conjuntos de hipóteses: o } \\
\text { modelo de design (requisitos, } \\
\text { tarefas, experiências do usuário } \\
\text { e capacidades), a imagem do } \\
\text { sistema (ambiente onde o } \\
\text { usuário interage) e o modelo do } \\
\text { usuário (interpretação que o } \\
\text { utilizador faz da interface do } \\
\text { sistema). }\end{array}$ & $\begin{array}{l}\text { Concepções da } \\
\text { Engenharia de } \\
\text { Usabilidade }\end{array}$ & $\begin{array}{l}\text { Desenvolvimento das relações } \\
\text { entre usuário e interface, } \\
\text { assegurando um alto grau de } \\
\text { qualidade e facilidade de uso. } \\
\text { Ciclo de concepção do projeto: } \\
\text { conhecer o usuário, análise } \\
\text { competitiva, definir metas de } \\
\text { usabilidade, protótipos, testes } \\
\text { empíricos, design iterativo e etc. } \\
\text { Ciclo de vida: } \\
\text { Análise de requisitos (metas de } \\
\text { usabilidade de acordo com as } \\
\text { tarefas, limitações e níveis de } \\
\text { usuários). } \\
\text { Design, Avaliação e } \\
\text { Desenvolvimento (conceber uma } \\
\text { solução que atenda as metas } \\
\text { estabelecidas na fase anterior). } \\
\text { Instalação (apreciações dos } \\
\text { usuários apontando soluções } \\
\text { e/ou necessidades de melhorias). }\end{array}$ \\
\hline $\begin{array}{l}\text { Lei de Hick- } \\
\text { Hyman }\end{array}$ & $\begin{array}{l}\text { Tempo x número de } \\
\text { possibilidades para tomar uma } \\
\text { decisão. }\end{array}$ & $\begin{array}{l}\text { Técnicas de } \\
\text { usabilidade }\end{array}$ & $\begin{array}{l}\text { - Visibilidade do status do } \\
\text { sistema. } \\
\text { - Compatibilidade do sistema } \\
\text { com o mundo real. } \\
\text { - Controle do usuário e } \\
\text { liberdade. } \\
\text { - Consistência e padrões. } \\
\text { - Prevenção de erros. } \\
\text { - Flexibilidade e eficiência de } \\
\text { uso. } \\
\text { - Estética e design minimalista. }\end{array}$ \\
\hline Lei de Fitts & $\begin{array}{l}\text { Tamanho e a localização de } \\
\text { elementos na interface }\end{array}$ & ISO 9241-11 & $\begin{array}{l}\text { Usabilidade, Eficácia, } \\
\text { Eficiência, Satisfação, Contexto } \\
\text { de uso, Sistema de trabalho, } \\
\text { Usuário, Objetivo, Tarefa, } \\
\text { Produto e Medida. }\end{array}$ \\
\hline Necessidades $w e b$ & $\begin{array}{l}\text { Disponibilidade, usabilidade, } \\
\text { confiança e desejo. }\end{array}$ & Triad funcional & $\begin{array}{l}\text { Ferramentas de IHC } \\
\text { persuasivas: } \\
\text {-simbólicas: ícones, gráficos, }\end{array}$ \\
\hline
\end{tabular}


VI Congresso Brasileiro de Informática na Educação (CBIE 2017)

Anais dos Workshops do VI Congresso Brasileiro de Informática na Educação (WCBIE 2017)

\begin{tabular}{|c|c|c|c|}
\hline & & & $\begin{array}{l}\text { imagens e textos. } \\
\text {-sensoriais: áudio, vídeo e } \\
\text { sensações de toque através dos } \\
\text { ambientes imersivos e virtuais. } \\
\text {-atores sociais: figuras } \\
\text { cibernéticas que agem como se } \\
\text { fossem reais para atuarem como } \\
\text { personagem persuasivo. }\end{array}$ \\
\hline $\begin{array}{l}\text { Modelo Humano } \\
\text { de Processamento }\end{array}$ & $\begin{array}{l}\text { Três sistemas humanos: } \\
\text { perceptivo (receptores: olhos, } \\
\text { ouvidos...), motor (atuadores: } \\
\text { saída) e cognitivo (memória). }\end{array}$ & $\begin{array}{l}\text { Concepções da } \\
\text { Engenharia } \\
\text { Semiótica }\end{array}$ & $\begin{array}{l}\text { Comunicação entre } \\
\text { desenvolvedores (designers), os } \\
\text { usuários e sistemas. Possui dois } \\
\text { níveis: comunicação direta } \\
\text { usuário-sistema e a } \\
\text { metacomunicação do designer } \\
\text { com o usuário através da } \\
\text { interface. }\end{array}$ \\
\hline $\begin{array}{l}\text { Princípios da } \\
\text { Gestalt }\end{array}$ & $\begin{array}{l}\text { Padrões de assimilação de } \\
\text { reconhecimento de informações } \\
\text { visuais. }\end{array}$ & & \\
\hline $\begin{array}{l}\text { Princípios } \\
\text { Persuasivos }\end{array}$ & $\begin{array}{l}\text {-Transformação de tarefas } \\
\text { complexas em atividades } \\
\text { simples. } \\
\text {-Orientação através de feedback. } \\
\text {-Apresenta a informação de } \\
\text { acordo com os interesses. } \\
\text {-Sugestões estratégicas. } \\
\text {-Permite recompensas a } \\
\text { determinadas ações do usuário. } \\
\text { Elementos éticos: } \\
\text {-resultados não podem cercear o } \\
\text { limite ético. } \\
\text {-motivações, métodos e } \\
\text { produtos devem ser visíveis aos } \\
\text { usuários; } \\
\text {-conscientização de } \\
\text { responsabilidade; } \\
\text {-respeito à privacidade; } \\
\text {-fornecimento de informações } \\
\text { fidedignas; } \\
\text {-não deve ocorrer em forma de } \\
\text { coação. } \\
\text { Forças de influência: } \\
\text {-escassez: quanto mais difícil, } \\
\text { mais atraente. } \\
\text {-autoridade: capaz de } \\
\text { influenciar comportamentos. } \\
\text {-reciprocidade e simpatia: } \\
\text { recompensa por uma atitude. } \\
\text {-similaridade social: } \\
\text { compartilhamento de interesses } \\
\text { em comum. } \\
\text {-compromisso e coerência: } \\
\text { comprometimento, } \\
\text { responsabilidade e engajamento. }\end{array}$ & & \\
\hline
\end{tabular}


Conforme visualizado no Quadro 1, as áreas científicas da psicologia e da computação e suas noções elementares foram desmembradas em suas características para proporcionar maior elucidação e entendimento do framework proposto. A área da psicologia foi considerada uma ciência substancial para a construção de interfaces persuasivas nesse estudo, através das estratégias de influência e dos elementos éticos, bem como a computação, enfatizando a engenharia de usabilidade e a abstração da engenharia semiótica na utilização dos signos para a comunicação entre desenvolvedores, usuários e sistemas.

O modelo concebido nesse trabalho está em fase de aplicação na interface do ambiente virtual de aprendizagem (AVA) Moodle, da Universidade Federal do Rio Grande, no contexto da disciplina Interação Humano-Computador, que é ofertada na modalidade presencial no segundo ano do curso de Sistemas da Informação. Salienta-se que as estratégias desenvolvidas pelo framework conceitual podem ser aplicadas em qualquer interface educacional, tanto desktop como mobile.

\section{Conclusões}

Pensar é uma instituição de produção do conhecimento, para isso o currículo pode ser sistematizado e organizado a partir da existência de necessidades, com intervenções tecnológicas que proporcionem vantagens, benefícios e incentivos para a coletividade. $\mathrm{O}$ framework conceitual construído para esse trabalho intenta incentivar a proficuidade da infraestrutura educacional utilizando as estratégias da psicologia e da computação. Sua aplicação em interfaces educacionais pode estabelecer interações produtivas entre pessoas, interfaces e tecnologias.

\section{References}

Araújo, G. (2013). Um framework conceitual para apoiar a instrumentação da avaliação formativa da aprendizagem em jogos digitais. Dissertação (Mestrado). Curso de Pós Graduação em Sistemas e Computação. Universidade Federal do Rio Grande do Norte: Natal.

Gil, A. (2008). Como elaborar projetos de pesquisa. 4. ed. São Paulo: Atlas.

Kitchenham, B. Brereton, P. Budgen, D. Turner, M. Bailey, J. Linkman, S. (2009). "Systematic literature reviews in software engineering - A systematic literature review". In: Information and Software Technology, v.51, p.7-15.

Kobashi, N. Santos, R. (2006). Institucionalização da pesquisa científica no Brasil: cartografia temática e de redes sociais. TransInformação, Campinas, v. 18, n. 1, p. 27-36.

Penido, A. (2016). Escolas em (re)construção. In: Destino Educação Escolas Inovadoras. São Paulo: Moderna. 